\title{
Prevalence and Predictors of Adverse Reactions to COVID-19 AstraZeneca Vaccine among Healthcare Staff of General Hospital Ilorin, North-Central, Nigeria
}

\author{
Christy O. Ademola, Adebayo R. Yusuf, Ismail A. Obalowu, and Abdulkadri Mohammed
}

\section{ABSTRACT}

Background: Vaccines are crucial for an effective global pandemic response. Despite the proven efficacy and safety of the COVID-19 AstraZeneca vaccine by the World Health Organization, some adverse effects have been reported.

\begin{abstract}
Aim: This was to determine the prevalence of adverse reactions to COVID19 vaccine among the healthcare workers, to assess the time of onset of symptoms after vaccination, to determine the total duration of persistent of symptoms after vaccination among respondents and to determine the sociodemographic and clinical predictors of adverse reactions among the participants.
\end{abstract}

Materials and Method: This study was a hospital-based descriptive crosssectional study, and it was conducted at the General Hospital Ilorin (GHI), Kwara State. The study population consists of 121 health workers at GHI who received the first dose of COVID-19 vaccine. Interviewers' administered questionnaires were used to obtain socio-demographic and some clinical information from the participants. Clinical measurements were done using weighing scale, stadiometer, stethoscope, and sphygmomanometer.

Results: The mean age of the participants was $39.5 \pm 8.9$. The most commonly reported adverse drug reactions (ADRs) among the participants were site tenderness $(51.2 \%)$, site pain $(51.2 \%)$, fatigue $(25.6 \%)$, and myalgia $(24 \%)$. There was no report of blood clotting problems among them $(0 \%)$. The majority of the ADRs started within 30 minutes to about 24 hours after the respondents received their COVID-19 vaccine jabs except for arthralgia which developed after 24 hours in the majority of the respondents who had it $(61.5 \%)$. Most of the ADRs resolved completely within 24 hours to 72 hours except for chills that lasted for less than $\mathbf{2 4}$ hours among the majority of the participants who had it $(\mathbf{5 3 . 3 \%})$, and also myalgia that lasted for more than 72 hours among the highest percentage of participants who reported having it $(41.4 \%)$. The results of the multiple logistic regression analysis revealed no statistically significant predictors for the reactions (All reported $P$-values for all the regression coefficients were greater than 0.05 ).

Conclusion: This study reported the prevalence, time of onset and duration of ARs to the first dose of AstraZeneca vaccine among health workers in Ilorin. The prevalence and pattern of the ARs reported is similar to those from other countries and continents. No report of severe anaphylactic reactions or blood clotting problems among the respondents. The time of onset and duration of most ARs were between 30 minutes to 24 hours, and less than 3 days respectively. The study also reported that no sociodemographic or clinical factors studied could significantly predict the occurrence of ARs among the participants.

Keywords: Adverse reactions, AstraZeneca COVID-19 vaccine, COVID-19, health care staff.
Submitted : September 13, 2021

Published : December 13, 2021

ISSN: $2593-8339$

DOI: $10.24018 /$ ejmed.2021.3.6.1060

\section{O. Ademola*}

General Hospital Ilorin, Kwara State, Nigeria.

(e-mail: ademolachristy@gmail.com)

R. A. Yusuf

University of Ilorin Teaching Hospital, Kwara State, Nigeria.

(e-mail: ameenanuhu@gmail.com)

I. A. Obalowu

General Hospital Ilorin, Kwara State, Nigeria.

(e-mail: obalowuismail@yahoo.com)

A. Mohammed

General Hospital Ilorin, Kwara State, Nigeria.

(e-mail: ludba886@gmail.com)

*Corresponding Author 


\section{INTRODUCTION}

Coronavirus disease 2019 (COVID-19) is a form of severe acute respiratory syndrome caused by a highly infectious novel virus (SARS-COV-2) that was first discovered as an outbreak in Wuhan City, Hubei Province of China [1]. It was first reported by World Health Organization (WHO) on the $31^{\text {st }}$ of December 2019, and it was declared a Public Health Emergency of International Concern on the $30^{\text {th }}$ of January 2020 [2]. On the $11^{\text {th }}$ of March 2020, WHO declared COVID19 as a global emergency [3].

COVID-19 has been exacting a huge toll on individuals, families, communities and societies across the world [4]. Daily lives have been profoundly changed and many economies worldwide have fallen into recession [4]. As of the $23^{\text {rd }}$ of August 2021, there have been 211, 373, 303 confirmed cases of COVID-19, including 4, 424, 341 deaths, reported by WHO globally [5]. Africa as a continent when compared with others, has the least number of confirmed COVID-19 cases with a total of 5, 459, 743 cases [5]. In Nigeria, as at the $23^{\text {rd }}$ of August 2021 there have been 187,023 confirmed cases of COVID-19, including 2,268 deaths [6]. The COVID-19 out-break started via zoonotic transmission associated with seafood market in Wuhan, China, later it was recognized that human to human transmission played a major role in subsequent outbreaks [7]. The disease primarily affects the respiratory system, although other organs systems could also be involved [8]. Commonly observed symptoms include fever, dry cough, dyspnea, headache, dizziness, generalized weakness, vomiting, and diarrhoea [9].

The high-risk individuals for COVID-19 include close contacts of infected persons, travelers arriving from highly infectious areas and health care workers caring for patients [7]. Alasia and Maduka in Rivers state, Nigeria reported COVID-19 prevalence of $15.4 \%$ among healthcare workers in the state [10]. This prevalence is considerably higher than the $5-12 \%$ prevalence rates reported in other parts of the world [11], [12].

*Precautionary measures to contain the spread of this virus include social distancing, isolation, wearing of facemasks, quarantine, community containment, national lockdowns and travelling restrictions [13], [14]. These measures are helping to control and reduce the spread but subsequently posing nations to economic recession [15]. The current medical management is largely supportive with no targeted therapy available [16]. Several drugs including Lopinavir-Ritonavir, Remdesivir, Hydroxychloroquine and Azithromycin have been tested in clinical trials but none of them have been proven to be a definitive therapy yet [17].

Hence, the need for primary prevention through vaccination to address the challenges of COVID-19. Presently, seven vaccines are authorized and recommended by the World Health Organization (WHO) to prevent COVID-19 related morbidities and mortalities; these are Pfizer-BioNTech, Moderna, Johnson and Johnson/Janssen, two versions of the AstraZeneca/Oxford COVID-19 vaccines (AstraZeneca - SKBio from Republic of Korea, and from Serum Institute of India), the Sinovac COVID-19 vaccine, and the Sinopharm COVID-19 vaccine [17]. As at $23^{\text {rd }}$ of August 2021, a total of 4, 615, 260, 567 vaccine doses have been administered globally [17]. Nigeria received 3.94 million doses of AstraZeneca/Oxford covid-19 vaccine shipped in via COVAX facility from Mumbai to Abuja to kick-start the first phase of COVID-19 vaccination which was targeted preferentially to all healthcare workers in the country in March 2021[18].

Vaccines are crucial for an effective global pandemic response [19]. The overall efficacy of AstraZeneca COVID vaccine is $70.4 \%$ [20]. Despite the efficacy and safety of the vaccine, some adverse effects have been reported. According to a WHO report, most of the adverse reactions (AR) to AstraZeneca vaccine were mild to moderate in severity and resolved within few days of vaccination [21]. Reactogenicity was generally milder and less frequent in older adults ( $\geq 65$ years old) compared to younger adults (18-64 years) [21]. In addition, the severity of the adverse reactions was milder in those receiving the second dose compared to the first dose [21]. The most frequently reported AR in the general population were injection site tenderness $(63.7 \%)$, injection site pain (54. 2\%), headache $(52.6 \%)$, fatigue $(53.1 \%)$, myalgia $(44.0 \%)$, malaise $(44.2 \%)$, pyrexia (33.6\%), chills (31.9\%), Arthralgia (26.4\%), nausea (21.9\%). Other uncommon observed neurologic adverse reactions were facial palsies, transverse myelitis, and new diagnosis of multiple sclerosis [21].

In the United Kingdom clinical trials on AstraZeneca COVID-19 vaccine involving more than 23,000 participants similar adverse events such as injection site tenderness, injection site pain, headache, fatigue, myalgia malaise, pyrexia, chills, arthralgia and nausea were reported in 1:10 people [22]. Also, the symptoms were mild to moderate in severity and resolved within few days. Similar presentations were observed among the age groups and with the administration of the second dose of the vaccine when compared with the WHO report [22].

There were some unproven facts that the Oxford/AstraZeneca vaccine causes blood clot formation in some recipients of the vaccine however, this was found to be untrue according to research done by European Medicine Agency, AstraZeneca vaccine has not been found to be linked with increased risk of blood clots [23].

Presently, very few studies have been reported about the adverse reactions to the AstraZeneca COVID-19 vaccine among healthcare workers in Nigeria, hence the need for this study. The healthcare workers are considered in this study because they are among the priority groups given the preference of receiving the vaccine earlier than the general population in the country. The aim of this study is to determine the prevalence and predictors of the adverse reactions to COVID-19 vaccine among healthcare workers at the General Hospital Ilorin. The specific objectives are to determine the prevalence of adverse reactions to COVID-19 vaccine among the healthcare workers, to assess the time of onset of symptoms after vaccination, to determine the total duration of persistent of symptoms after vaccination among respondents and to determine the socio-demographic and clinical predictors of adverse reactions among the participants.

\section{Methodology}

This study was a hospital-based descriptive cross-sectional study, and it was conducted at the General Hospital Ilorin 
(GHI). The hospital is in the heart of the Ilorin metropolis and offers primary, secondary, and tertiary medical services. Ilorin is the capital of Kwara state, in the North-central geopolitical zone of Nigeria. The study population consists of all health workers at the GHI, aged 18 years and above who received the first dose of COVID-19 vaccine and who satisfied the inclusion criteria. Sample size was estimated using formula for estimating minimum sample size for health studies by Leslie Kish to arrive at 121 participants. Therefore, a total of 121 consenting health workers participated in the study. Stratified random sampling technique was used to recruit eligible participants across different categories of healthcare staff in the hospital without bias. The inclusion criterion was all consenting healthcare workers at the General Hospital Ilorin (GHI) who received COVID 19 vaccine. Healthcare workers excluded from the study were those who did not receive the vaccine, and others, such as pregnant women and breastfeeding mothers.

In accordance with the Helsinki Declaration, the study was approved by the Ethical Review Committee of GHI while each participant voluntarily gave an informed consent. Structured and semi-structured interviewer administered questionnaires developed by the authors were used to obtain socio-demographic and some clinical information from the participants; including the nature of Adverse Drug Reaction (ADR) they experienced after receiving the COVID-19 vaccine, the time of onset of the ADR, the duration of the ADR before resolution, history of previous ADR to other vaccines, history of chronic medical illness, and history of past COVID-19 positive test. The weights of the participants were obtained using Camry Digital Personal Weighing Scale $^{\mathrm{TM}}$ (Hong Kong), and the Seca 274 Free Standing Stadiometer $^{\mathrm{TM}}$ (United Kingdom) was used for the height's measurement. The Dekamet Accoson Mercury Sphygmomanometer MK. ${ }^{\mathrm{TM}}$ (England) and Littmann Classic Stethoscope ${ }^{\mathrm{TM}}$ was used to measure participants' blood pressure.

\section{A. Study Protocol}

Each selected participant signed an informed consent form and was administered the study questionnaire. Thereafter, the body mass index (BMI) of the participants was calculated from weight $(\mathrm{kg}) /$ height $^{2}\left(\mathrm{~m}^{2}\right)$. The blood pressure of each patient was measured by auscultatory method using a standard mercury sphygmomanometer with appropriately sized cuff and a Littmann stethoscope. This was done in keeping with recommended guidelines [24].

\section{B. Data Analysis}

The collected data was sorted, coded and entered into the computer for analysis using the Statistical Package for Social Sciences Version 21 (SPSS-21). Results were presented using frequency tables. Multiple logistic regression analysis was used to assess significant socio-demographic and clinical predictors of common COVID-19 adverse reactions among the participants. The level of significance of this study was set at $5 \%(\mathrm{p}<0.05)$.

\section{RESUlTS}

\section{A. Socio-demographic Characteristics of the Participants}

The mean age of the participants was $39.5 \pm 8.9$ and the highest percentage of the participants was those within the $30-39$ age group. There was a female preponderance in the study population with female to male ratio of $2: 1$ and the highest population of healthcare workers in the study were nurses $(37.2 \%)$. The results are displayed in Table I.

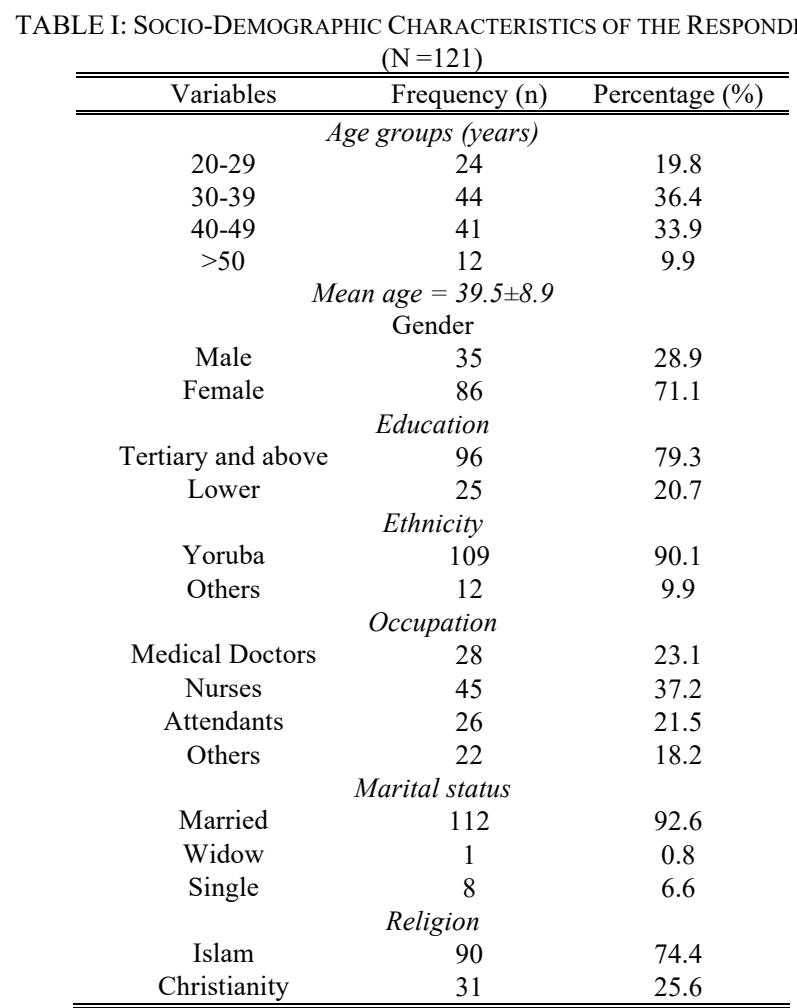

\section{B. Prevalence of COVID-19 Vaccine Associated Adverse Reactions among the Respondents}

The most commonly reported ADR among the participants were site tenderness $(51.2 \%)$, site pain $(51.2 \%)$, fatigue $(25.6 \%)$, and myalgia (24\%). There was no report of blood clotting problems among them $(0 \%)$. The results are displayed in Table II.

TABLE II: PREVALENCE OF COVID-19 VACCINE ASSOCIATED ADVERSE REACTIONS AMONG THE RESPONDENTS

\begin{tabular}{ccc}
\hline \hline \multirow{2}{*}{ Adverse Reactions } & \multicolumn{2}{c}{ Frequency $(\mathrm{n})$} \\
\cline { 2 - 3 } Site tenderness & $59(48.8)$ & $62(51.2)$ \\
Site warmness & $109(90.1)$ & $12(9.9)$ \\
Site pain & $59(48.8)$ & $62(51.2)$ \\
Headache & $93(76.9)$ & $28(23.1)$ \\
Fatigue & $90(74.4)$ & $31(25.6)$ \\
Myalgia & $92(76.0)$ & $29(24.0)$ \\
Malaise & $101(83.5)$ & $20(16.5)$ \\
Fever & $100(82.6)$ & $21(17.4)$ \\
Chills & $106(87.6)$ & $15(2.4)$ \\
Arthralgia & $108(89.3)$ & \\
Nausea & $13(10.7)$ & $4(3.3)$ \\
Body itching & $117(96.7)$ & $3(2.5)$ \\
Rash & $118(97.5)$ & $1(0.8)$ \\
Blood clotting problem & $120(99.2)$ & \\
Others & $121(100.0)$ & $0(0.0)$ \\
Excessive hunger & $108(89.3)$ & $13(10.7)$ \\
Sleepiness & & $3(2.5)$ \\
\hline \hline
\end{tabular}




\begin{tabular}{cc}
\hline \hline Diarrhea & $5(4.0)$ \\
Dizziness & $2(1.7)$ \\
Menorrhagia & $2(1.7)$ \\
\hline \hline
\end{tabular}

\section{Time of Onset of Common Adverse Reactions among the} Respondents

Majority of the ADRs started within 30 minutes to about 24 hours after the respondents received their COVID-19 vaccine jabs except for arthralgia which developed after 24 hours in the majority of the respondents who had it (61.5\%). The results are shown in Table III.

TABLE III: TIME OF ONSET OF COMMON ADVERSE REACTIONS AMONG

\begin{tabular}{|c|c|c|c|c|}
\hline $\begin{array}{c}\text { Adverse } \\
\text { Reactions }\end{array}$ & $\begin{array}{l}\text { Onset } \\
\text { (hour) }\end{array}$ & $\begin{array}{c}\text { Frequency } \\
\text { (n) }\end{array}$ & Total $(\mathrm{N})$ & $\begin{array}{c}\text { Percentage } \\
(\%)\end{array}$ \\
\hline \multirow{3}{*}{$\begin{array}{c}\text { Site } \\
\text { tenderness }\end{array}$} & $<0.5$ & 5 & & 8.1 \\
\hline & $0.5-24$ & 42 & & 67.7 \\
\hline & $>24$ & 15 & 62 & 24.2 \\
\hline \multirow{3}{*}{$\begin{array}{c}\text { Site } \\
\text { warmness }\end{array}$} & $<0.5$ & 2 & & 16.7 \\
\hline & $0.5-24$ & 10 & & 83.3 \\
\hline & $>24$ & 0 & 12 & 0.0 \\
\hline \multirow{3}{*}{ Site pain } & $<0.5$ & 5 & & 8.1 \\
\hline & $0.5-24$ & 42 & & 67.7 \\
\hline & $>24$ & 15 & 62 & 24.2 \\
\hline \multirow{3}{*}{ Headache } & $<0.5$ & 2 & & 7.1 \\
\hline & $0.5-24$ & 20 & & 71.5 \\
\hline & $>24$ & 6 & 28 & 21.4 \\
\hline \multirow{3}{*}{ Fatigue } & $<0.5$ & 1 & & 3.2 \\
\hline & $0.5-24$ & 21 & & 67.8 \\
\hline & $>24$ & 9 & 31 & 29.0 \\
\hline \multirow{3}{*}{ Myalgia } & $<0.5$ & 5 & & 17.2 \\
\hline & $0.5-24$ & 18 & & 62.1 \\
\hline & $>24$ & 6 & 29 & 20.7 \\
\hline \multirow{3}{*}{ Malaise } & $<0.5$ & 5 & & 25.0 \\
\hline & $0.5-24$ & 12 & & 60.0 \\
\hline & $>24$ & 3 & 20 & 15.0 \\
\hline \multirow{3}{*}{ Fever } & $<0.5$ & 4 & & 19.0 \\
\hline & $0.5-24$ & 11 & & 52.4 \\
\hline & $>24$ & 6 & 21 & 28.6 \\
\hline \multirow{3}{*}{ Chills } & $<0.5$ & 1 & & 6.7 \\
\hline & $0.5-24$ & 8 & & 53.3 \\
\hline & $>24$ & 6 & 15 & 40.0 \\
\hline \multirow{3}{*}{ Arthralgia } & $<<0.5$ & 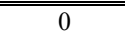 & & 20.0 \\
\hline & $0.5-24$ & 5 & & 38.5 \\
\hline & $>24$ & 8 & 13 & 61.5 \\
\hline
\end{tabular}

\section{Duration of Common Adverse Reactions Experienced by} the Respondents

Majority of the ADRs resolved completely within 24 hours to 72 hours except for chills that lasted for less than 24 hours in the majority of the participants who had it (53.3\%), and also myalgia that lasted for more than 72 hours among the highest percentage of participants who reported having it (41.4\%). The results are shown in Table IV.

TABLE IV: DURATION OF COMMON ADVERSE REACTIONS EXPERIENCED

\begin{tabular}{ccccc}
\multicolumn{5}{c}{ BY THE RESPONDENTS } \\
\hline \hline $\begin{array}{c}\text { Adverse } \\
\text { Reactions }\end{array}$ & $\begin{array}{c}\text { Onset } \\
\text { (hour) }\end{array}$ & $\begin{array}{c}\text { Frequency } \\
(\mathrm{n})\end{array}$ & Total $(\mathrm{N})$ & $\begin{array}{c}\text { Percentage } \\
(\%)\end{array}$ \\
\hline \multirow{2}{*}{ Site } & $<24$ & 13 & & 21.0 \\
tenderness & $24-72$ & 33 & 62 & 53.2 \\
& $>72$ & 16 & & 25.8 \\
\hline \multirow{2}{*}{ Site } & $<24$ & 3 & 12 & 25.0 \\
warmness & $24-72$ & 7 & & 53.3 \\
& $>72$ & 2 & 62 & 16.7 \\
\hline \multirow{2}{*}{ Site pain } & $<24$ & 13 & & 21.0 \\
& $24-72$ & 35 & & 56.4 \\
& $>72$ & 14 & 28 & 21.4 \\
\hline \multirow{2}{*}{ Headache } & $<24$ & 6 & & 57.2 \\
& $24-72$ & 16 & & 21.4 \\
\hline \multirow{2}{*}{ Fatigue } & $>72$ & 6 & 31 & 12.9 \\
& $<24$ & 4 & & 25.8 \\
\hline
\end{tabular}

\begin{tabular}{ccccc}
\hline \multirow{3}{*}{ Myalgia } & $<24$ & 6 & & 20.7 \\
& $24-72$ & 11 & 29 & 27.9 \\
& $>72$ & 12 & & 41.4 \\
\hline \multirow{3}{*}{ Malaise } & $<24$ & 3 & 20 & 15.0 \\
& $24-72$ & 14 & & 70.0 \\
& $>72$ & 3 & & 15.0 \\
\hline \multirow{3}{*}{ Fever } & $<24$ & 5 & 21 & 61.9 \\
& $24-72$ & 13 & & 14.3 \\
\hline \multirow{3}{*}{ Chills } & $>72$ & 3 & 15 & 53.3 \\
& $<24$ & 8 & & 40.0 \\
& $24-72$ & 6 & & 6.7 \\
\hline \multirow{3}{*}{ Arthralgia } & $>72$ & 1 & 13 & 69.8 \\
& $<24$ & 4 & & 0.0 \\
\hline \hline
\end{tabular}

E. Multiple Logistic Regression Analysis for the Predictors of Common Adverse Reactions among the Participants

The results of the multiple logistic regression analysis done to determine significant socio-demographic and clinical predictors of the common adverse reactions reported by the participants revealed no statistically significant predictors for the reactions (All reported P-values for all the regression coefficients were greater than 0.05$)$. The results are shown in Table V.

TABLE V: MULTIPLE LOGISTIC REGRESSION ANALYSIS FOR THE PREDICTORS OF COMMON ADVERSE REACTIONS AMONG THE PARTICIPANTS

\begin{tabular}{|c|c|c|c|}
\hline Site tenderness & $\begin{array}{c}\text { Regression } \\
\text { Co-efficient } \\
\text { (r) } \\
\end{array}$ & $\begin{array}{c}\text { Degree of } \\
\text { Column } \\
(\mathrm{df}) \\
\end{array}$ & P-value (P) \\
\hline Age & 0.04 & 1 & 0.904 \\
\hline BMI & -0.02 & 1 & 0.958 \\
\hline Blood pressure & -0.19 & 1 & 0.508 \\
\hline Being a male sex & -0.72 & 1 & 0.286 \\
\hline Being of Islamic religion & 0.10 & 1 & 0.875 \\
\hline Being married & 1.65 & 1 & 0.182 \\
\hline $\begin{array}{l}\text { Having tertiary } \\
\text { education }\end{array}$ & 0.25 & 1 & 0.647 \\
\hline $\begin{array}{c}\text { Being of Yoruba } \\
\text { ethnicity }\end{array}$ & 1.10 & 1 & 0.285 \\
\hline Being a medical doctor & 0.06 & 1 & 0.925 \\
\hline $\begin{array}{l}\text { Not being managed for } \\
\text { chronic medical } \\
\text { disease }(\mathrm{s})\end{array}$ & -1.92 & 1 & 0.111 \\
\hline $\begin{array}{l}\text { Having no past history of } \\
\text { vaccine ADR }\end{array}$ & -0.86 & 1 & 0.390 \\
\hline $\begin{array}{c}\text { No past positiveCOVID- } \\
19 \text { test }\end{array}$ & 1.09 & 1 & 0.305 \\
\hline \multicolumn{4}{|l|}{ Fatigue } \\
\hline Age & -0.05 & 1 & 0.382 \\
\hline BMI & 0.34 & 1 & 0.130 \\
\hline Blood pressure & -0.07 & 1 & 0.115 \\
\hline Being a male sex & 0.82 & 1 & 0.400 \\
\hline Being of Islamic religion & 1.75 & 1 & 0.072 \\
\hline Being married & 1.20 & 1 & 0.419 \\
\hline $\begin{array}{l}\text { Having tertiary } \\
\text { education }\end{array}$ & 49.23 & & 0.991 \\
\hline $\begin{array}{c}\text { Being of Yoruba } \\
\text { ethnicity }\end{array}$ & 0.54 & 1 & 0.707 \\
\hline Being a medical doctor & -1.44 & 1 & 0.064 \\
\hline $\begin{array}{l}\text { Not being managed for } \\
\text { chronic medical } \\
\text { disease }(\mathrm{s})\end{array}$ & -0.94 & 1 & 0.498 \\
\hline $\begin{array}{c}\text { Having no past history of } \\
\text { vaccine ADR }\end{array}$ & -1.62 & 1 & 0.214 \\
\hline $\begin{array}{c}\text { No past positiveCOVID- } \\
19 \text { test } \\
\end{array}$ & -0.21 & 1 & 0.989 \\
\hline \multicolumn{4}{|l|}{$\begin{array}{ll}\text { Myalgia } \\
\end{array}$} \\
\hline Age & -0.03 & 1 & 0.659 \\
\hline BMI & 0.67 & 1 & 0.160 \\
\hline Blood pressure & -0.07 & 1 & 0.071 \\
\hline Being a male sex & 2.39 & 1 & 0.056 \\
\hline Being of Islamic religion & 0.48 & 1 & 0.592 \\
\hline Being married & -0.73 & 1 & 0.727 \\
\hline Having tertiary & 15.26 & 1 & 0.997 \\
\hline
\end{tabular}




\begin{tabular}{cccc}
$\begin{array}{c}\text { Being of Yoruba } \\
\text { ethnicity }\end{array}$ & 1.96 & 1 & 0.434 \\
$\begin{array}{c}\text { Being a medical doctor } \\
\begin{array}{c}\text { Not being managed for } \\
\text { chronic medical } \\
\text { disease(s) }\end{array}\end{array}$ & 1.12 & 1 & 0.325 \\
$\begin{array}{c}\text { Having no past history of } \\
\text { vaccine ADR }\end{array}$ & -0.55 & 1 & 0.704 \\
$\begin{array}{c}\text { No past positiveCOVID- } \\
19 \text { test }\end{array}$ & -1.43 & 1 & 0.399 \\
\hline \hline
\end{tabular}

\section{DISCUSSION}

This study revealed that about half of the participants had site pain and tenderness following AstraZeneca COVID-19 vaccination at the hospital. Other very common ADRs reported in the study with prevalence of $>20 \%$ were fatigue $(25.6 \%)$, myalgia (24\%), and headache $(23.1 \%)$. No report of the dreaded blood clotting problems or severe anaphylactic reactions in the study population. The study also reported that the majority of the ADRs experienced by the participants commenced within 30 minutes to 24 hours of vaccination and that most of them resolved within 1-3 days. The assessment of possible socio-demographic or clinical variables that can predict the occurrence of the common ADRs in this study, revealed no significant predictors for them.

The local ADRs of site pain and tenderness reported as the most common ADRs in this study have also been reported to be the most common side effects of COVID-19 vaccines in most studies among healthcare workers and in the general population in different countries [21], [25], [26]. Likewise, a study carried out among healthcare workers who received different type of COVID-19 vaccines (AstraZeneca Vaxzevria, Pfizer-BioNTeck, and SinoPharm) also reported site tenderness as the most frequent side effect [26]. Similarly, close to half of participants in a study done in the UK also had local side effects while a higher percentage of $68.9 \%$ of the respondents reported pain at the injection site in a hospital based Nigerian study [21], [27]. The varying pain threshold of individuals as well as different injection techniques may be possible reasons for the variations observed. Furthermore, the prevalence of site warmness reported in this study is comparable to that seen in similar study elsewhere [21].

For systemic symptoms observed in this study, the most prevalent ADRS reported were fatigue (25.6\%), myalgia $(24.0 \%)$, and headache $(23.1 \%)$ in that order. These findings were quite similar to the findings among healthcare workers who received COVID-19 vaccines in Jordan in the order of the three commonest systemic ADRs reported but their prevalences were significantly higher than the ones in this study [25]. A similar study done among the healthcare workers in Saudi Arabia also revealed fatigue (90\%) as the most prevalent ADR, and it was even higher than the prevalence of local symptoms reported in that study [28]. The prevalences of fever and chills reported in this study is comparatively lower than the findings among health workers in South-South Nigeria where $57 \%$ and $43.7 \%$ of respondents had fever and chills following AstraZeneca COVID-19 vaccination [27]. The higher prevalence of fever and chills observed in South-South Nigeria might be due to differences in the weather condition.
Body itching and rash were among the least prevalent ADRs seen in this study. These symptoms, though less prevalent in most studies, were also part of the allergic symptoms seen in the United States following the first dose of Pfizer-BioNTech COVID-19 Vaccine [29]. Blood clotting conditions or problems were not observed in any recipient. This is in line with the statement released by the WHO Global Advisory Committee on Vaccine Safety that the AstraZeneca COVID-19 vaccine continues to have a positive benefit-risk profile, and that the available data do not suggest any overall increase in clotting conditions such as deep venous thrombosis or pulmonary embolism following administration of COVID-19 vaccines [30]. Other systemic symptoms such as diarrhea, dizziness, were observed in few participants as seen in other studies. [28].[30] Among respondents who received different COVID-19 vaccines, it has been reported that the AstraZeneca vaccine had comparatively higher chance of causing systemic ADRs than PB and SinoPharm vaccines [26]. This might also affect the pattern and prevalence of ADRs experienced in such population.

In this study, most of the adverse reactions (ARs) to AstraZeneca COVID-19 vaccine (local and systemic) occurred within the interval of 30 minutes to 24 hours following the vaccine administration. This short onset and duration are in keeping with previous studies and clinical trials done on the vaccine. A study by [31] discovered that fatigue and headache were the mostly reported systemic side effects within the 24 hours of receiving COVID-19 vaccine, and that they lasted 1.01 days. They also reported that tenderness and local pain around the site occurred most often on the day after injection and lasting 1.02 days [31]. Reference [32] in a study on safety and immunogenicity of AstraZeneca vaccine found that the most common solicited local adverse reactions, which include site pain, tenderness, warmth, redness, and induration, occurred most frequently in the first 48 hours after vaccination. According to a study done by [33] in the Republic of Korea on impact of the side effects of COVID-19 vaccines (AstraZeneca and Pfizer) on work productivity among health care workers, it was found out that these side effects occurred within $12 \mathrm{hrs}$ after vaccination in a quarter of the health care workers in the AstraZeneca group, although most of these side effects disappeared in less than 48 hours. In a similar study done among health workers in the South-South Nigeria, it was reported that the onset of most side-effects of the AstraZeneca vaccines was on the first day and that all the side effects resolved within a week [27].

Also, in this study, multiple socio-demographic and clinical parameters such as age, BMI, blood pressure, sex, religion, marital status, level of education, ethnicity, health care professional categories, history of chronic medical disease(s), past history of vaccine adverse drug reaction and history of past positive COVID-19 test were all tested to determine significant predictors of the commonly reported adverse reactions in the study. However, no statistically significant predictor was found for all the ADRs tested. This finding is not surprising given that most vaccines related ADRs are usually unpredictable. However, researchers like [31] have been able to detect some significant associations between COVID-19 vaccines ADRs and some sociodemographic and clinical parameters. They reported that the proportion of participants who reported at least one systemic 
and local effects after the first dose of AstraZeneca vaccine were significantly higher among people aged 55 years or younger than those older than 55 years [31]. They also reported that women were more likely to report adverse effects than men and that individuals vaccinated with a first dose of inoculation were more likely to report both local and systemic effects if they had a previous SARS Cov-2 positive result than those without [31]. Further high-powered studies are needed to fully establish if the studied factors have any predictive value in determining the pattern of ARs following COVID-19 vaccination among healthcare workers and in the general population. This study is limited by its relatively smaller study population, its cross-sectional design, and the possibility of recall bias from the participants. There is no doubt that the findings from this study would form an important bedrock for further studies and has contributed important data in further deepening of knowledge on COVID-19 vaccination related ADRs among healthcare workers.

\section{CONCLUSION}

This study was able to report the prevalence, time of onset and duration of ARs to the first dose of AstraZeneca vaccine among health workers in Ilorin. The prevalence and pattern of the ARs reported is similar to those from other countries and continents. No report of severe anaphylactic reactions or blood clotting problems among the respondents. The time of onset and duration of most ARs were between 30 minutes to 24 hours, and less than 3 days respectively. The study also reported that no socio-demographic or clinical factors studied could significantly predict the occurrence of ARs among the participants.

\section{REFERENCES}

[1] Zhu N, Zhang D, Wang W, Li X, Yang B, Song J, et al. China Novel Corona Virus Investigating and Research Team A Novel Corona virus from patients with pneumonia in China. $N$. Engl J Med. 2020; 382: 727733.

[2] Gallego A. WHO declares Public Health Emergency for Novel Corona virus. Medscape medical news [Online] 2020. [cited on 2021 $\begin{array}{llll}\text { September } & 9] & \text { Available } & \text { from: }\end{array}$ https://www.medscape.com/viewarticle/924596.

[3] WHO. WHO Director-General's Opening remarks at the media briefing in Covid-19 [Online] 2020. [cited on 2021 September 9] Available from: https://www.who.int/directorgeneral/speeches/detail/who-director-general-s-opening-remarks-atthe-media-briefing-on-covid-19---11-march-2020.

[4] WHO. COVID-19 Strategy Update 14th of April 2020, [Online] 2020. [cited on 2021 September 9] Available from: https://www.who.int/publications/i/item/covid-19-strategy-update--14-april-2020.

[5] WHO. COVID-19 Dashboard. [Online] 2021. [cited on 2021 August 23] Available from: https://covid19.who.int/.

[6] NCDC. COVID-19 Nigeria Dashboard. [Online] 2021. [cited on 2021 August 23] Available from: https://covid19.ncdc.gov.ng/.

[7] Li Q, Guan X, Wu P, Wang X, Zhou L, Tong Y, et al. Early transmission dynamics in Wuhan China of novel coronavirus-infected pneumonia. N Engl J Med. 2020; 382: 1199-1207.

[8] Huang C, Wang Y, Li X, Ren L, Zhao J, Hu Y, et al. Clinical features of patients infected with 2019 novel coronavirus in Wuhan China. Lancet. 2020; 395: 497-506.

[9] Shi H, Han X, Jiang N, Cao Y, Alwalid O, Gu J, et al. Radiological findings from 81 patients with COVID-19 pneumonia in Wuhan China, A descriptive study. Lancet Infect Dis. 2020; 20: 425-434.
[10] Alasia DD, Maduka O. Prevalence and pattern of COVID-19 among healthcare workers in Rivers State, Nigeria. Occupational Diseases and Environmental Medicine. 2021; 9: 20-32.

[11] Al-Kuwari MG, AbdulMalik MA, Al-Nuaimi AA, Abdulmajeed J, AlRomaihi HE, Semaan S, et al. Epidemiology characteristics of COVID19 infection amongst primary health care workers in Qatar: MarchOctober 2020. Frontiers in Public Health. 2021; 9: 570.

[12] Sabetian G, Moghadami M, Hashemizadeh FH, Shahriarirad R, Fallahi MJ, Asmarian N, et al. COVID-19 infection among healthcare workers: a cross-sectional study in southwest Iran. Virol J. 2021; 18: 58.

[13] Bohoslavsky JP. United Nation's Human Right. (COVID-19: Urgent appeal for a human rights response to the economic recession. [Online] 2020. Available from: https//www.ohchr.org/Documents /issues/Development /IE debt/202004114 IE Debt_urgent_appeal_Covid19_EN. Pdf.

[14] Counterpoint. Weekly Update Global Corona virus impact and implications. [Online] 2021. Available from: https://www.counterpoint research.com/coronavirus-weekly-update/.

[15] Covid-19 Pandemic. Impact of Restrictions Measures in West Africa. [Online] 2021. Available from: http://www.reliefweb.int.

[16] Yuki K, Fugiogi M, Koutsogiannaki S. COVID-19 Pathophysiology: a review. Clinical Immunology. 2020; 215.

[17] WHO. COVID-19 vaccines: product-by-product information. [Online] 2021. Available from: https://www.who.int/emergencies/diseases/novel-coronavirus2019/covid-19-vaccines.

[18] COVID-19 vaccines shipped by COVAX arrive in Nigeria. [Online] 2021. Available from: [hpp://www.afro.who.int $>$ news $>$ covid 19.

[19] Hung IFN, Poland G. Single dose Oxford - AstraZeneca covid 19 vaccine followed by a 12-week booster. The Lancet. 2021; 397: 854855.

[20] Voysey M, Clemens SAC, Madhi SA, Weckx LY, Folegatti PM, Aley $\mathrm{PK}$, et al. Safety and efficacy of ChAdOx 1 nCov-19 vaccine (AZD1222) against SARS-CoV-2 an interim analysis of four randomized controlled trials in Brazil, South Africa and the UK. The Lancet. 2021; 397: 99-111.

[21] WHO. AZD1222 vaccine against COVID-19: developed by Oxford University and AstraZeneca background paper. Draft prepared by the Strategic Advisory Group of Experts (SAGE) an immunization working group on COVID-19 vaccine. [Online] 2021. Available from: https://www.who.int/publications/i/item/WHO-2019-nCoV-vaccines-.

[22] Gov.UK. Research and analysis coronavirus vaccine - weekly summary of yellow card report. Medicine and Health care products Regulatory Agency. [Online] 2021. Available from: www.gov.uk.

[23] Mahase E. European Medicine Agency. Covid 19: AstraZeneca vaccine has been found not linked to increased risk of blood clots. $B M J$. $2021 ; 372$.

[24] Smith L. New AHA recommendations for blood pressure measurement. Am Fam Physician. 2005; 72: 1391-6.

[25] Abu-Hammad O, Alduraidi H, Abu-Hammad S, Alnazzawi A, Babkair $\mathrm{H}$, Abu-Hammad A, et al. Side effects reported by Jordanian healthcare workers who received COVID-19 vaccines. Vaccines (Basel). 2021; 9: 577.

[26] Zhang MX, Zhang TT, Shi GF, Cheng FM, Zheng YM, Tung TH, et al. Safety of an inactivated SARS-CoV-2 vaccine among healthcare workers in China. Expert Rev Vaccine. 2021; 13: 1-8.

[27] Oriji PC, Allagoa DO, Obagah L, Oguche OI, Ohaeri OS, Tekenah ES, et al. Side effect profile of COVID-19 vaccine among health workers in a tertiary health Institution in South-South Nigeria. European Journal of Medical and Health Sciences. 2021; 3: 59-64.

[28] Alhazmi A, Alamer E, Daws D, Hakami M, Darraj M, Abdelwahab S, Maghfuri A, Algaissi A. Evaluation of Side Effects Associated with COVID-19 Vaccines in Saudi Arabia. Vaccines (Basel). 2021; 9: 674.

[29] Shimabukuro T, Nair N. Allergic reactions including anaph ylaxis after receipt of the first dose of Pfizer-BioNTech COVID-19 vaccine. JAMA.2021; 325: 780-781.

[30] WHO. Global Advisory Committee on Vaccine Safety statement. Online] 2021. Available from: https://www.who.int/news/item/19-032021-statement-of-the-who-global-advisory-committee-on-vaccinesafety-(gacvs)-covid-19-subcommittee-on-safety-signals-related-tothe-astrazeneca-covid-19-vaccine.

[31] Menni C, Klaser K, May A, Polidori L, Capdevila J, Louca P, et al. Vaccine side-effects and SARS-CoV-2 infection after vaccination in users of the COVID Symptom Study App in the UK: a prospective observational study. Lancet Infect Dis. 2021; 21: 939-949.

[32] Ramasamy MN, Minassian AM, Ewer KJ, Flaxman AL, Folegatti PM, Owens DR, et al. Safety and immunogenicity of ChAdOx $1 \mathrm{n} \mathrm{Ca}-19$ vaccine administered in a prime-boost regimen in young and old adults (COV 002). A single-blind randomized controlled phase $2 / 3$ trial. The Lancet. 2021; 396: 1979-1993. 
[33] Kim T, Park Y, Yu S, Park JW, Lee E, Jeon MH, et al. Impacts of side effects to BNT162b2 and the first dose of ChAdOx1 Anti-SARS-CoV2 vaccination on work productivity, the need for medical attention, and vaccine acceptance: a multicenter survey on healthcare workers in referral teaching hospitals in the Republic of Korea. Vaccines. 2021; 9: 648.

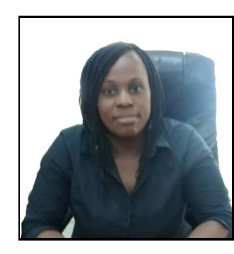

C. O. Ademola was born on the $17^{\text {th }}$ of May; 1979. She completed her primary and secondary education in Ogbomoso Oyo state, Nigeria in the years 1990 and 1996 respectively. She obtained her medical degree from Ladoke Akintola University of Technology Ogbomoso, Nigeria in the year 2007. Thereafter, she proceeded for her residency training in family medicine specialty in 2012 at the University of Ilorin Teaching Hospital Ilorin Kwara State where she obtained a fellowship certificate from West African College of Physicians in 2018 .

She has worked in several hospitals; she did her INTERSHIP at the University College Hospital, Ibadan, Oyo State in 2007, YOUTH CORPER MEDICAL OFFICER in 2008, and as a MEDICAL OFFICER in a private hospital in 2009 before she proceeded for residency training. She is presently working as a MEDICAL CONSULTANT and RESIDENCY TRAINING COORDINATOR at the General Hospital Ilorin Kwara State Nigeria; She has three publications in local journals.

Dr. Ademola is a member of Nigeria Medical Association, Society of Family Physician and Medical and Dental Consultant Association of Nigeria.

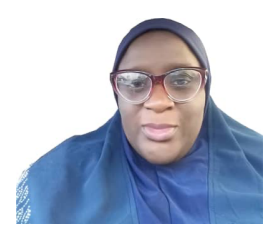

A. R. Yusuf was born on $27^{\text {th }}$ of October 1982 . She completed her primary and secondary education in Ilorin, Kwara State in the years 1993 and 1999 respectively. She obtained her medical degree at the University of Ilorin Nigeria in the year 2008. Thereafter, she proceeded for her residency training in family medicine in 2012 at the University of Ilorin Teaching Hospital where she obtained a fellowship certificate from National Postgraduate Medical College of Nigeria in 2018.

She has worked in various hospitals: she did her Intership in University of Ilorin in 2008 to 2009, served as youth corper doctor in 2009 to 2010 , medical officer at a Basic Health Centre in Kwara State from 2010 to 2012 before proceeding for residency in 2012. She is presently working as a hospital consultant and postgraduate residency TRAINER at the University of Ilorin Teaching Hospital Ilorin Kwara State. She has a publication in a local journal.

Dr. Yusuf is a member of Society of Family Physician, Medical and Dental Consultant Association of Nigeria and Nigeria Medical Association.

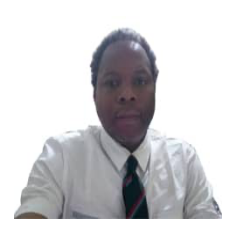

I. A. Obalowu was born on the $11^{\text {th }}$ of February 1981. He completed his primary and secondary education in Ilorin in the years 1991 and 1998 respectively. He obtained his medical degree (MBBS) at the University of Ilorin, Nigeria in the year 2007. Thereafter, he proceeded for his residency training in family medicine in 2010 at the University of Ilorin Teaching Hospital Ilorin, where he obtained a Fellowship certificate in Family Medicine from the West African College of Physicians in 2016.

$\mathrm{He}$ is presently working as a consultant family physician and head of department of Family Medicine, General Hospital Ilorin, Kwara State, Nigeria. He presently has six publications in both local and international journals.

Dr. Obalowu is a member of the Nigeria Medical Association, Society of Family Physicians of Nigeria and Medical and Dental Consultants Association of Nigeria.

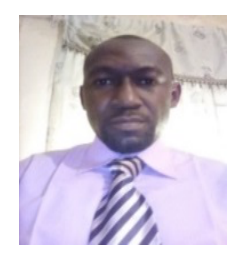

A. Mohammed was born on the $28^{\text {th }}$ of December 1978. He completed his primary and education in Ilorin in the years 1990 and 1996 respectively. He obtained his medical degree at the University of Ilorin, Nigeria in the year 2004. Thereafter, he proceeded for his residency training in family medicine at the University of Ilorin Teaching Hospital Ilorin where he obtained a Fellowship certificate in Family Medicine from West African College of Physicians in 2016

$\mathrm{He}$ is presently working as a consultant family physician at the department of family medicine, General Hospital Ilorin, Kwara State, Nigeria.

Dr. Mohammed is a member of the Nigeria Medical Association, Society of Family Physicians of Nigeria and Medical and Dental Consultants Association of Nigeria. 